\title{
Moedas romanas além das fronteiras, o caso do Norte da Europa
}

\author{
Tomás Partiti*
}

\begin{abstract}
PARTITI, T. Moedas romanas além das fronteiras, o caso do Norte da Europa. R. Museu
\end{abstract} Arq. Etn., 32: 151-158, 2019.

Resumo: As moedas romanas em contextos do norte da Europa se destacam por serem o conjunto de objetos romanos de maior ocorrência no além-fronteira. São produto de relações políticas específicas, que estão ligadas aos contextos históricos das fronteiras no início da antiguidade tardia e além. Em todo o escopo temporal em que elas estão em circulação, dos séculos III d.C. ao V d.C., teremos as seguintes denominações: denários, sestércios, aureus e solidus, cada uma representando períodos diversos da história do Império Romano na antiguidade tardia. Essas denominações são vistas em uma vasta extensão territorial na qual se encontram os seguintes países apresentados neste texto: Alemanha, Polônia, Suécia e Dinamarca. O artigo busca apresentar as visões da literatura contemporânea para as interpretações e contextos que servem de base para a circulação das moedas romanas para além fronteira.

Palavras chave: Numismática; Fronteiras; Moedas; Denário; Solidus.

\section{Introdução}

$A^{s}$ s moedas romanas em contextos norte-europeus se encontram em uma categoria à parte de objetos romanos, uma vez que são os de maior ocorrência. De denominações diversas, elas são dispersas em uma área grande que abrange países como Alemanha, Suécia, Dinamarca e chega a atingir a Polônia.

Este grande conjunto possui uma diversidade de denominações as quais estão ligadas a períodos específicos tanto de produção, quanto de circulação. As moedas possuem

(*) Mestre em Arqueologia pelo MAE/USP. Pesquisador do Laboratório de Arqueologia Romana Provincial, LARP-MAE/ USP < bythomaspartiti@gmail.com> dois horizontes diversos que têm de ser explicados. O primeiro é o horizonte de produção, o qual varia de acordo com a denominação e posteriormente o horizonte de deposição das moedas.

Devemos destacar que este horizonte de deposição é pautado por estudos de tesouros. Este grupo de achados, em sua classificação mais básica, é entendido como acúmulos de duas ou mais moedas, sendo produto de uma ação emergencial, instantânea, ou acúmulo deliberado e de longa duração.

Dentro das cronologias, temos as produções monetárias em um horizonte que compreende o período entre os séculos II-V d.C., sendo que as moedas têm as seguintes cronologias de produção: II-III d.C, para os denários e sestércios, III-IV d.C, para os aureus e IV-V d.C. para os solidii. Já seus contextos de circulação e deposição caminham entre os séculos III-V d.C. 
Moedas romanas além das fronteiras, o caso do Norte da Europa

R. Museu Arq. Etn., 32: 151-158, 2019.

\section{Critérios de seleção}

Neste estudo trabalhamos com conjuntos e perspectivas levantadas por pesquisadores dos seguintes países: Polônia, Dinamarca e Suécia. Também contamos com a catalogação e levantamento de conjuntos alemães com o intuito de demonstrar o alcance geográfico da circulação desses tesouros.

Determinados os parâmetros de seleção primários seguimos com a seleção do material, dentro das possibilidades de levantamento dos dados de maneira acurada. Esta seleção resultou nas seguintes denominações que foram selecionadas no trabalho aqui apresentado: Denários, Sestércios, Aureus e Solidus.

Delimitadas as denominações caminhamos para as análises do material selecionado de forma a caracterizar as seguintes informações: denominação, autoridade emissora, período de produção e eventualmente o peso das unidades pertencentes aos tesouros selecionados.

Os levantamentos foram produzidos através de uma série de bancos de dados e catálogos impressos. Para a pesquisa foram levantados dados dos seguintes repositórios: o AFE-WEB, para as denominações alemãs, AFE-WEB PL, para os achados poloneses, além do banco de imagens do gabinete numismático da Universidade de Berlim. No caso dos tesouros suecos, contamos com a colaboração do Professor Lennart Lind, que nos cedeu, muito gentilmente, uma cópia impressa do catálogo de sua autoria sobre denários romanos encontrados na Suécia.

As seleções resultaram em três tesouros de ouro, constituídos de Aureus e Solidus, e sete tesouros de prata, composto de Denários. São os seguintes tesouros: Neuhaus e Gräpel, tesouros de prata alemães; Gierloz e Frombork, tesouros de prata poloneses; Gandarve II b, Buters/ Rovide e Öster Ryftes, tesouros de prata suecos. Já para os tesouros de ouro temos Zargózyn e Trabike Male, Polônia, e Boltinggard Skov, Dinamarca.

Esta seleção por si já reflete a predominância dos denários sobre as outras denominações. Aleksander Bursche, em seus estudos sobre a numismática romana nos contextos poloneses, destaca esse predomínio que será visto de maneira ampla não só na Polônia como também na Dinamarca e Suécia (Bursche 2006).

\section{Análise dos conjuntos}

Nesse escopo temos dois conjuntos de análises numismáticas, a tipológica, que trabalha as características iconográficas e epigráficas da moeda, e as análises dos tesouros, aqui constituídas dos dados tipológicos de cada moeda, no tocante às informações que pautaram a nossa seleção previamente apresentada.

Os tesouros selecionados apresentam certas características em comum, para isso as tipologias se tornam importantes para determinarmos, como apresentado anteriormente, as questões de denominação, autoridade emissora e período de produção. Assim podemos ver uma série de aspectos constituintes dos tesouros selecionados, da prevalência de produções de períodos específicos, como os denários da dinastia antonina e a predominância de solidii do século IV, no caso dos tesouros de ouro.

Quanto às moedas de ouro, temos tanto produções do governo sediado em Constantinopla, quanto o baseado em Roma em diversas oficinas, uma vez que a produção era descentralizada. Já a produção dos denários está concentrada na oficina de Roma.

Outro elemento importante das análises deste material é a cronologia de constituição dos tesouros. Essa periodização se torna possível a partir da construção de uma cronologia de produção das moedas. É a partir da análise tipológica que conseguimos inferir as datações de produção das moedas pertencentes aos tesouros. Desse modo, buscamos os seguintes dados: a datação de produção da moeda mais antiga e a da mais recente.

O dado mais importante seria o das moedas mais recentes uma vez que é com esta data que podemos pensar não só na duração da atividade de entesouramento, como também em hipóteses para a cronologia de circulação das moedas encontradas no norte da Europa. 


\section{4.}

\subsection{Interpretação dos achados}

Conforme apresentado anteriormente, os achados são tesouros de uma variedade considerável de denominações. Como argumenta Bursche (2002:2), elas teriam sido produto de relações políticas entre os povos locais e Roma. As informações que possuímos para podermos interpretar vêm das fontes textuais romanas e dos estudos das moedas, uma vez que não temos informações textuais sobre as práticas locais.

Outro elemento que pode contribuir são as análises de contextos de achado, partindo do pressuposto de que os tesouros tenham sido produto de uma escavação arqueológica acurada e os dados produzidos tenham sido documentados de forma correta.

Quando temos casos desta natureza podemos, de forma mais efetiva, construir entendimentos das práticas locais. Já em situações em que não possuímos essas informações devemos seguir por uma rota de análise dos objetos a partir de uma perspectiva antropológica proposta por Bursche (2002).

Nesse aspecto, a análise é pautada por três etapas, as quais estão ligadas ao processo que levou a moeda ao seu contexto estrangeiro. São elas: circulação, transformação e deposição. Nessas etapas a pesquisa busca compreender quais são as agências nas moedas, tanto romanas, quanto locais, além do processo que resulta na saída das mesmas dos contextos romanos e sua recepção e novas práticas atribuídas a elas pelos povos locais.

No quesito circulação, esta se sustenta a partir das motivações para os usos das moedas romanas. Bursche argumenta que elas teriam sido produto de transações motivadas por questões políticas ou sociais, caracterizadas como tributos, dotes, heranças, resgates. Outro elemento seriam as trocas de presentes entre membros das elites locais que justificariam a estrutura de poder local que estava emergindo na antiguidade tardia, através do controle sobre a obtenção das moedas (Bursche 2002).

Esta flutuação ocorre a partir da distância dos povos do norte da Europa do poder emissor romano. Isso resulta em uma flutuação do valor das moedas uma vez que as transações variam em função dos interesses pessoais dos indivíduos envolvidos na negociação (Bursche 2002).

$\mathrm{O}$ aspecto de transformação é importante para entendermos as práticas locais atribuídas às moedas e desse modo compreender como serão usadas nas sociedades locais do norte e centro da Europa. Bursche apresenta alguns meios de utilização das moedas nos contextos locais. Eles seriam: uso de moedas em colares, a partir das moedas romanas e a imagem do imperador, as quais teriam o objetivo de ser um bem de prestígio, que indica a importância do usuário através da exibição da efígie imperial. Outro meio de utilização das moedas seria o de fonte de metal precioso, de prata bronze e ouro, as quais teriam sido reutilizadas para a produção de pingentes e outros ornamentos feitos de metal (Bursche 2002).

No último elemento, a deposição, Bursche argumenta que o simbolismo das moedas teria sido um motor para uma deposição de caráter ritual, uma vez que as moedas são itens de status. Ao mesmo tempo, ritos de passagem também teriam um papel importante na deposição das moedas em contextos do norte da Europa, de rituais para a construção de casas a oferendas (Bursche 2002).

No caso escandinavo, não temos grandes mudanças quanto à natureza do material e seus contextos. De forma geral o denário é a denominação de maior ocorrência, sendo encontrado em depósitos em sítios ou em pântanos, em que o caráter ritual fica evidente (Fig. 1).

Uma questão importante é a diferença na quantidade de achados entre os países que compõem o nosso escopo geográfico. Bursche aponta que nos contextos escandinavos há no máximo 10 mil denários, os quais se encontram em grande parte na ilha de Goatland, na Suécia. Já para os contextos poloneses haveria 60 mil unidades (Bursche 2006). As estruturas cronológicas apontam uma unidade entre os achados escandinavos e os continentais, a partir da predominância dos denários do século II d.C., ao mesmo tempo seria no final deste século que as moedas teriam saído do poder romano rumo aos povos germânicos, não passando do período de governo de Septímio Severo. 


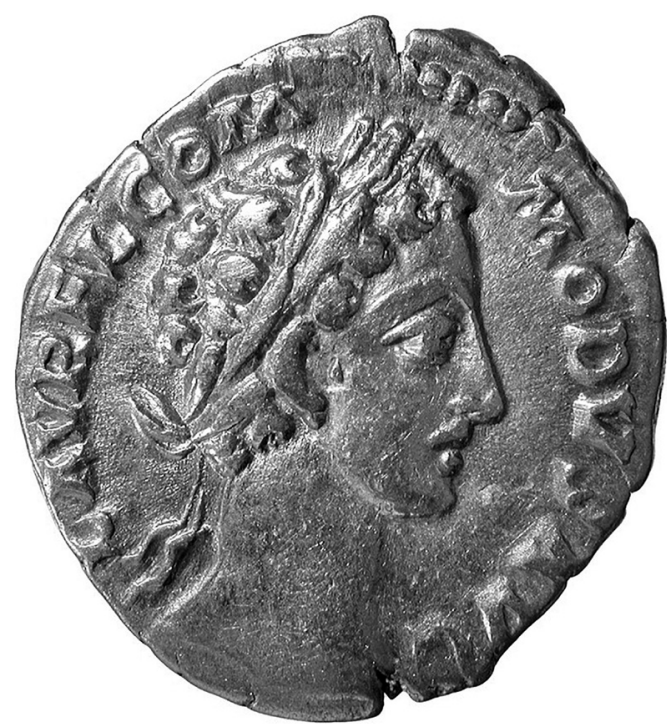

Fig 1. Exemplo de denário emitido por Marco Aurélio, encontrado no tesouro de Gierloz.

Fonte: http://numismatics.org/ocre/

Helle Horsnaes em seu estudo de Bornholm aponta que há predominância dos denários da dinastia antonina, o que também é visto em certos tesouros continentais (Horsnaes 2010). Os desgastes são vistos de forma bastante proeminente, algo esperado para as moedas romanas em contextos escandinavos. Lennart Lind também aponta este desgaste nos denários na Suécia (Lind 2013).

No universo dos denários, o tesouro de Frombork é interessante para que possamos entender algumas práticas dos povos germânicos no tocante às moedas romanas. $\mathrm{O}$ tesouro teria pertencido a um ouvires que viajaria oferecendo seus serviços e joias. As moedas pertencentes a este tesouro são compreendidas como matéria prima para a produção de joias. Esta inferência é produto da associação do tesouro com outros objetos como fragmentos de joias não terminadas que indicam este propósito (Zapolska 2014).

Frombork possui algumas especificidades que merecem destaque e tornam o tesouro especial. Primeiro a sua composição, ele é um tesouro misto de denários, sestércios e solidii. Desse modo, há uma longa duração na constituição do tesouro uma vez que a moeda mais recente é do século $\mathrm{V}$, solidus de Teodósio II, e seus denários estão no horizonte do século II.
Assim temos um grande período de circulação das diferentes denominações até sua deposição no conjunto aqui apresentado (Zapolska 2014).

No caso das denominações de ouro, o tesouro de Boltinggard Skóv se torna um exemplo interessante para compreendermos a ocorrência das denominações de ouro, as práticas a elas associadas em contextos escandinavos e as novas rotas de circulação em meio aos novos agentes na antiguidade tardia.

O tesouro de Boltinggard Skóv é misto, com 15 moedas de ouro e um bracelete com marcações romanas. Este conjunto possui algumas características interessantes quanto ao seu caráter deposicional que nos mostra algumas práticas locais rituais. $\mathrm{O}$ achado ocorreu entre 1867 e 96 durante uma expansão nos campos de cultivo dinamarqueses, expansão essa que rumou para áreas que até então não tinham sido ocupadas.

Após este primeiro contato, ocorreram pesquisas na área entre 1987 e 2004, que resultaram em novas adições ao tesouro. A deposição deste conjunto está ligada ao sítio de Gudme, este um assentamento de elite localizado na ilha de Funen. Segundo Henrikesen e Horsnaes (2006), o tesouro teria sido uma oferenda para proteção das fronteiras deste assentamento ou para apaziguar as forças da natureza que estão à espreita nas zonas fronteiriças

A circulação de moedas de ouro no período de 300 d.C. a 450 d.C. está pautada por algumas questões específicas, como a mudança de denominação padrão para as transações monetárias romanas. Neste período o solidus surge como moeda padrão para os contextos a partir do século IV d.C., e com isso há uma predominância das emissões comissionadas pela autoridade imperial situada em Constantinopla. Essas emissões serão distribuídas para o Ocidente, retrabalhadas e postas em circulação novamente a partir do século $\mathrm{V}$ d.C. Como apontam Fischer e Sanchez, essas emissões ocidentais surgem a partir da chegada de moedas de Constantinopla nas oficinas de Ravenna e Milão com o intuito de serem reutilizadas na produção de novas moedas (Fischer \& Sanchez 2016).

Desse modo, tesouros como Trabike Male e o solidus do tesouro de Frombork, na Polônia, 
explicam sua origem, uma vez que possuem moedas produzidas sob a autoridade de Constantinopla (Fig.2). Assim, temos que pensar possíveis rotas de circulação e possíveis justificativas históricas para a ocorrência deste material nos contextos do Báltico.

Mais uma vez retomamos Fischer para entendermos que este horizonte numismático de Trabike Male é produto de uma redistribuição de tesouros das ilhas escandinavas para as elites do norte da Polônia. Assim, este tesouro teria entrado nos contextos do norte da Europa a partir das relações entre as elites locais escandinavas e os novos reinos germânicos em solo romano (Fishcer \& Sanchez 2016). Esta redistribuição também deve ser entendida como motor da circulação interna entre norte da Europa de forma mais ampla nos contextos das denominações de ouro desse período.

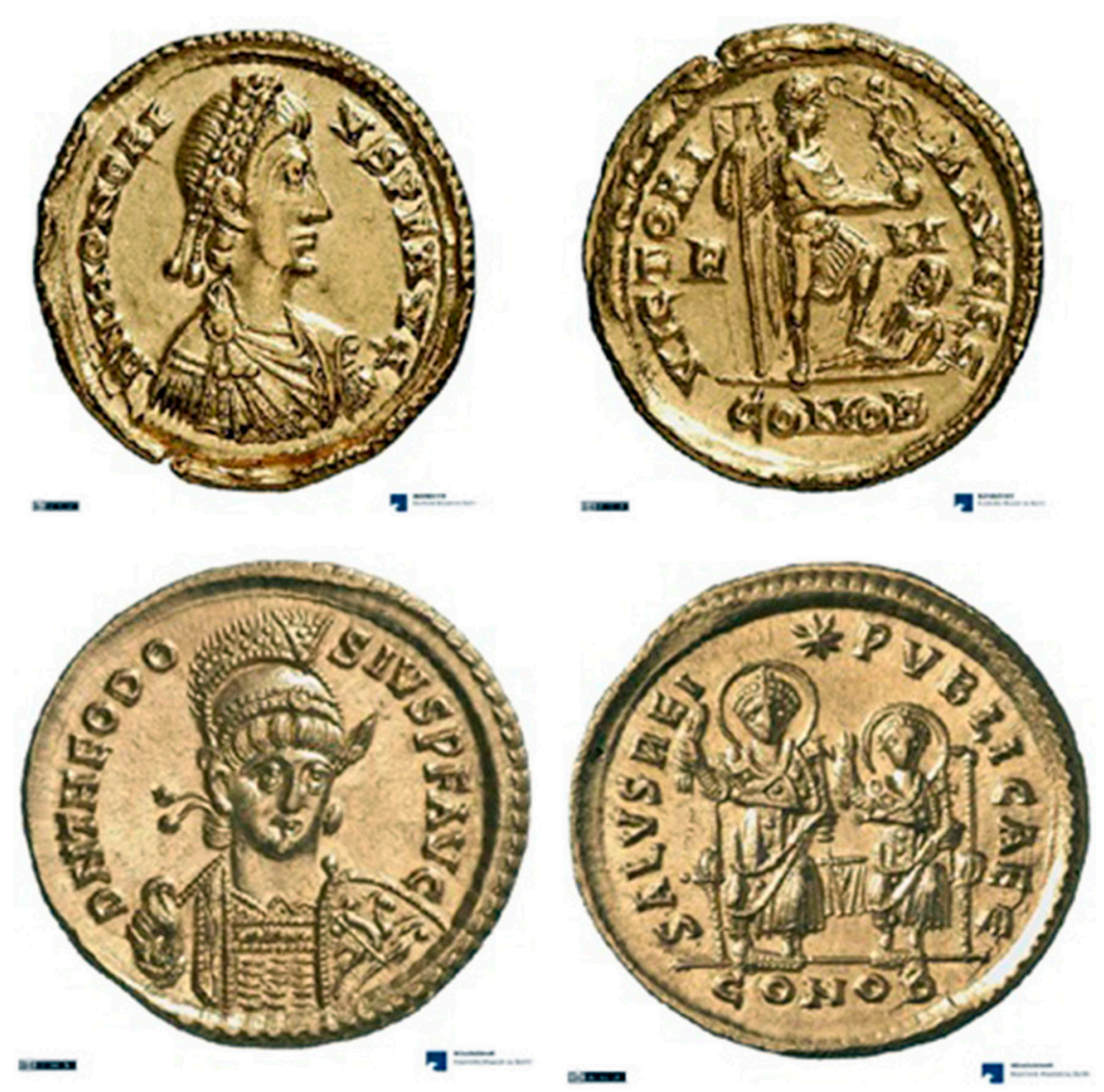

Fig 2. Exemplo das moedas de maior ocorrência no tesouro de Trabike Male, solidii de Teodósio II e Honório. Fonte: https://ikmk.smb.museum/home?lang=en

\subsection{Os povos locais do centro e norte da} Europa, sociedade e o contato com a cultura material romana

As denominações apresentadas anteriormente são recebidas por grupos locais do centro e norte da Europa. Estes são percebidos através da cultura material, uma vez que não temos fontes textuais indígenas, assim recorremos aos arqueólogos para podermos traçar quais seriam os povos locais que ocupavam os territórios nos quais foram encontrados os tesouros.

Primeiro, devemos apresentar a forma como os arqueólogos determinaram as categorias de cultura material correspondentes ao período de contato com Roma e produzidas pelos povos locais. A criação de culturas arqueológicas se torna o meio de construir categorias para que possamos, através da materialidade, compreender e categorizar as sociedades locais. 
Moedas romanas além das fronteiras, o caso do Norte da Europa R. Museu Arq. Etn., 32: 151-158, 2019.

Nos contextos apresentados temos duas culturas arqueológicas distintas, a Przeworsk e a Wielbark. A primeira está na porção central da Polônia, já a segunda tem seu local de concentração no extremo norte da Polônia, na foz do rio Vístula. As categorias aqui apresentadas foram constituídas a partir de uma extensa pesquisa e catalogação de conjuntos de objetos e práticas, tendo em vista construir padrões e estabelecer quais seriam os modos de ocupação, estratificação, produção e práticas rituais dos povos locais.

Bartoz Kontny nos apresenta um grande levantamento da cultura Przeworsk buscando entender em que consistiam sua produção, consumo, práticas funerárias e organização social. Aqui vemos algumas categorias de objetos romanos, além das moedas, que possuem agência nos contextos locais: seriam elas as esporas e espadas. Estas são encontradas em contextos funerários em profusão, uma vez que na cultura Przeworsk os enterramentos de armas eram em grande quantidade, e ao mesmo tempo pertencentes a uma elite militar que negocia e participa dos contatos com o mundo romano (Kontny 2016).

A ocorrência deste material estaria ligada a duas possibilidades de acordos entre os assentamentos Przeworsk e Roma. A primeira seria um acordo para a constituição da rota do âmbar, uma vez que o trajeto desse material vindo do litoral do Báltico teria de passar por territórios de grupos pertencentes à cultura Przeworsk (Kontny 2016:167).

Outro elemento importante para as relações de contato entre esse grupo e as fronteiras de Roma são os movimentos rumo ao sul. Estes possivelmente ligados ao envolvimento, segundo Kontny, dos membros da cultura Przeworsk na guerra da Dácia e nas guerras contra os Macromanii; segundo Kontny as espadas romanas encontradas em territórios Przeworsk teriam sido produto da participação nesse conflito datando da segunda metade do século II d.C. até o início do século III d.C. (Kontny 2016:170). Já o envolvimento na guerra da Dácia, é visível no registro arqueológico a partir da presença de cultura material Przeworsk, datada da primeira metade do século II d.C., em sítios no oeste da Ucrânia e na Eslováquia (Kontny 2016: 169).
A cultura Wielbark nasce no norte da Polônia, na região da foz do rio Vístula e no Golfo de Gdansk, e seu horizonte cronológico está balizado entre os séculos I d.C.-V d.C. Suas populações estão em um mesmo horizonte social da cultura Przeworsk, porém seus enterramentos não possuem armamentos. Em contrapartida, temos as esporas como marcadores sociais nos contextos funerários deste grupo. Assim, temos uma relevância da cavalaria para a distinção social nos grupos Wielbark, do mesmo modo que vemos nos outros grupos tanto no continente como na Escandinávia (Cieśliński 2016).

A ação direta dos membros deste grupo, na obtenção de objetos romanos, é produto de sua migração rumo ao sul atraídos pela força da zona de fronteira do Império Romano. Agência esta que pode ser entendida a partir de vários dos seguintes métodos: diplomacia, pagamentos de tributos, saques, resgates e comércio (Cieśliński 2016).

É neste horizonte de estratificação social que vemos a emergência de elites locais escandinavas, segundo Lotte Hedeager (1992), teríamos uma elite cavaleira ocupando posições de destaque no mundo escandinavo, o que é percebido através da presença de esporas e cabrestos nos contextos arqueológicos locais. Segundo a autora, o poder desta elite se estrutura a partir da redistribuição de bens de prestígio a outros membros deste grupo, com o intuito de reforçar os laços de diplomacia entre as diversas lideranças locais. É a capacidade de obter bens de prestígio, romanos por exemplo, o meio de reforçar o poder local das elites pelo controle ao acesso a esses artigos.

Neste debate devemos considerar uma questão importante para a circulação, não só das moedas, como também de outros objetos romanos para o centro e norte da Europa. Teriam as elites locais entrado em contato com Roma através da participação nas guerras sendo tropas auxiliares ou seriam os povos locais, tanto escandinavos quanto poloneses, federados do Império Romano? Quais seriam as motivações para Roma buscar atrair esses grupos para sua esfera de influência? 


\subsection{Federados ou auxiliares, o debate para a estrutura básica das relações entre Roma e os povos locais}

Thomas Grane, em sua tese, busca analisar a questão para a sociedade escandinava e levanta alguns pontos interessantes. $\mathrm{O}$ autor associa a presença de objetos romanos finos como indicativos de relações sociais mais complexas entre as elites locais e Roma, desde a presença de armamentos até vasilhas de bronze (Grane 2007).

Nas duas hipóteses, de federação ou de atuação militar, pode ocorrer uma variação entre as motivações para a ocorrência desse material nos contextos locais. Caso a hipótese de federados se consolide, as moedas se tornam pagamentos diplomáticos para a celebração do tratado entre a elite local e Roma. Ao mesmo tempo, a contrapartida seria atender às demandas do império conforme elas surgissem ou das monarquias romano-germânicas do século $\mathrm{V}$ d.C.

Aqui devemos apontar a presença de outros objetos de metal de origem romana, as vasilhas de bronze e prata. Se levarmos em consideração a presença de objetos de metal como meio de circulação de valor por intermédio do peso e não do suporte, podemos cogitar que a circulação de metal transcende o suporte moeda nas celebrações de tratados diplomáticos.

Se a hipótese de tropas auxiliares se concretiza, a presença das moedas de prata indica, nos tesouros, uma eventual ligação com os pagamentos aos serviços dos soldados. Ao mesmo tempo, as moedas seriam encontradas nos contextos locais devido à ausência de estabilidade dessa categoria de soldados romanos. Essa ausência estruturaria o eventual retorno desses bens, com os seus respectivos donos/soldados, a seus locais de origem devido ao término dos conflitos nos quais participavam, no caso dos denários as guerras macromanas (Bursche 2002).

Desse modo, temos três possiblidades distintas para a chegada desse material no tocante a questões de circulação. Seja por via de circulação direta, Roma levando as moedas aos seus contextos de achado. Por via da circulação de pessoas, soldados retornando para seus respectivos lares. Ou por circulação local, por via de redistribuição entre elites. Cada uma com um grau distinto de agência dos respectivos atores nos contextos de circulação monetária romana.

O que não podemos negar é o caráter político das relações entre os povos continentais e escandinavos com Roma. A forma com que a ocorrência das moedas em contextos do norte e centro da Europa é caracterizada não nos permite pensar em outras justificativas para as denominações de maior ocorrência, denários e as emissões de ouro.

A presença de outros objetos romanos, como armas e vasos de bronze, nos permite entender quais os estratos sociais que negociam com Roma. Esses grupos possuem características que os definem como uma incipiente elite militar no século II d.C. e que vai se consolidar no século III d.C., sendo produto direto do contato com a cultura material romana e das necessidades do Império Romano, traduzidas aqui na presença dos tesouros de moedas romanas em contextos da Escandinávia e Polônia.

PARTITI, T. Roman coins beyond frontiers, the Northern European case. R. Museu Arq. Etn., 32: 151-158, 2019.

Abstract: Roman coins in Nothern European contexts are the category of Roman goods of highest quantity beyond the Roman European frontier. They are product of a set of historical contexts and of political relations in the beginning of late antiquity and beyond. Throughout the centuries, from III B.C. to V AD, we have a variety of denominations that are present, in the geographical setting of this research, e.g: denarii, sestertii, aureii and solidii. Those coins are seen in a vast geographical landscape that represents modern day Germany, Poland, Denmark and Sweden. This paper aims to 
Moedas romanas além das fronteiras, o caso do Norte da Europa

R. Museu Arq. Etn., 32: 151-158, 2019.

present the current state of research, the interpretations and settings that are understood as the basis for the circulation of Roman currency beyond the European frontier.

Keywords: Numismatics; Frontiers; Coins; Denarii; Solidii.

\section{Referência bibbliográficas}

Bursche, A. 2006. Relations between the Late Roman World and Barbariam Europe in the light of the coin finds. Bulletin du Cercle d'Études Numismatiques, volume 43: 221-227.

Bursche, A. 2002. Circulation of Roman Coinage in Northern Europe in Late Antiquity, Histoire \& Mesure, volume 17, França.

Cieśliński. A. 2016. The society of Wielbark culture, AD 1-300, In: Rzeszotarska-Nowakiewicz, A. (Ed.) Past Societies. Institute of Archaeology and Ethnology, Polish Academy of Sciences, vol 4:217-255, Varsóvia.

Grane, Thomas. 2007. The Roman Empire and Southern Scandinavia - A Northern Connection! Tese de doutorado, University of Copenhagen, Copenhague.

Hedeager, L. 1992. Iron-age Societies From Tribe to State in Northern Europe 5 BC to AD 700. Blackwell Publishers, Londres.

Horsnaes, H. W. 2010. Roman Coins From Bornholm- A preliminary Overview. In: Hansen, U. L.; \& Wróblewska, A. B. (Eds.) Worlds apart? contacts across the Baltic Sea in the Iron Age; network Denmark - Poland, 2005 - 2008. Copenhagen University Press, volume7: 433-447, Copenhagen.

Kontny, B. 2016. Przeworsk culture society and its long-distance contacts, AD 1-350, In: Rzeszotarska-Nowakiewicz, A. (Ed.) Past Societies. Institute of Archaeology and Ethnology, Polish Academy of Sciences, vol 4: 163-216, Varsóvia.

Lind, L. 2013. Roman Denarii Hoards and Stray Finds in Sweden, volume 1. Stockholm University, Estocolmo.

Wells. P. S. 1998. The Barbarians Speak How the Conquered peoples shaped Roman Europe. Princeton University Press, Princeton, N. J.

Whittaker, C. R. 1997. Frontiers of the Roman Empire, A social and Economic Study. The Johns Hopkins University Press, EUA.

Zapolska, A. 2014. The Coins from the Goldsmith of Frombork Reconsidered. Notae Numismaticae, volume 9: 95-115 